\title{
Some remarks on the Krasnoselskij iterative method
}

\section{DAN ŞTEFAn MARINESCU and MiHai MONEA}

\section{ABSTRACT.}

In this paper we deal with some convergence results regarding the Krasnoselskij iterative scheme. New proofs for known results like Proposition 3.2 or Theorem 1.1 as well as new results like Proposition 3.4 or Proposition 4.5, are presented.

Acknowledgments. The authors would like to thank the editor and reviewer for their careful reading of the manuscript and for many valuable comments and suggestions that improved its initial version.

\section{REFERENCES}

[1] Balaj, M., Introducere în teoria $K^{2} M$, Editura Universităţii din Oradea, Oradea, 2003

[2] Bailey, D. F., Krasnoselski's theorem on the real line, Amer. Math. Monthly, 81 (1974), No. 5, 506-507

[3] Berinde, V., Iterative Approximation of Fixed Points, Springer, Berlin Heidelberg New York, 2007

[4] Berinde, V. and Kovacs, V., Stabilizing discrete dynamical systems by monotone Krasnoselskij type iterative schemes, Creative Math. Inform., 17 (2008), No. 3, 298-307

[5] Browder, F. E. and Petryshyn, W. V., Construction of fixed points of nonlinear mappings in Hilbert space, J. Math. Anal. Appl., 20 (1967), No. 2, 197-228

[6] Cegielski, A., Iterative Methods for Fixed Point Problems in Hilbert Spaces, Lecture Notes in Mathematics, 2057, Springer, Heidelberg, 2012

[7] Chidume, C. E., Geometric Properties of Banach Spaces and Nonlinear Iteration, Springer, Berlin Heidelberg New York, 2009

[8] Chidume, C. E. and Măruşter, Şt., Iterative methods for the computation of fixed points of demicontractive mappings, J. Comput. Appl. Math., 234 (2010), 881-882

[9] Granas, A. and Dugundji, J., Fixed Point Theory, Springer Monographs in Mathematics, Springer-Verlag, New York, 2003

[10] Hillam, B. P., A characterization of the convergence of successive approximations, Amer. Math. Monthly, 83 (1976), No. 4, 273

[11] Ishikawa, S., Fixed points and iterations of a nonexpansive mapping in a Banach space, Proc. Amer. Math. Soc., 59 (1976), 65-71

[12] Krasnoselskij, M. A., Two remarks on the method of successive approximations (in Russian), Uspehi Mat. Nauk., 10 (1955), No. 1 (63), 123-127

[13] Marinescu, D. S., Monea, M., Opincariu, M. and Stroe, M., Some equivalent characterizations of inner product spaces and their consequences (submitted)

[14] Petryshyn, W. V., Construction of fixed points of demicompact mappings in Hilbert space, J. Math. Anal. Appl., 14 (1966), $276-284$

[15] Petryshyn, W. V. and Williamson, T. E., Jr., Strong and weak convergence of the sequence of successive approximations for quasi-nonexpansive mappings, J. Math. Anal. Appl., 43 (1973), 459-497

[16] Rotaru, F., Problem 26689, Gazeta Matematică (B), 117 (2012), No. 11, 540

[17] Thele, R. L., Iterative techniques for approximation of fixed points of certain nonlinear mappings in Banach spaces, Pacific J. Math., 53 (1974), $259-266$

Colegiul naţional "IAncu de Hunedoara"

HUNEDOARA, ROMANIA

E-mail address: marinescuds@gmail.com

Colegiul național "DeCebal"

DEVA, ROMANIA

E-mail address: mi haimonea@yahoo.com

* Dedicated to Professor Emeritus Constantin Corduneanu on the occasion of his 85th birthday

Received: 15.01.2013; In revised form: 15.07.2013; Accepted: 18.07.2013

2010 Mathematics Subject Classification. 47H09, 47H10, 54H25.

Key words and phrases. Hilbert space, nonexpansive operator, fixed point, Krasnoselskij iteration. 